\title{
High Quality Differentiated Instruction - A Checklist for Teacher Professional Development on Handling Differences in the General Education Classroom
}

\author{
Wouter Smets \\ Karel de Grote University College, Belgium
}

Copyright $\subset 2017$ by authors, all rights reserved. Authors agree that this article remains permanently open access under the terms of the Creative Commons Attribution License 4.0 International License

\begin{abstract}
This paper presents a checklist that scaffolds teachers' professional decision-making with regard to differentiated instruction. It discusses the way the concept of differentiated instruction may be applied in an evidence-informed way by presenting a checklist for high-quality differentiated instruction (DI). We tried to tackle the question of how to implement differentiated instruction in a research-informed way. We sought answers in meta-analyses on effective teaching practices. To investigate accordance between this literature and two models for DI, all elements in these models were operationalized. We scrutinized whether the operational elements in these models are characterized by effectivity as effective teaching practices. The result is an evidence-informed checklist that helps teachers who want to apply the concept of DI in their practice which consists of three sets of criteria: (1) the teachers in relation to the students; (2) the teacher and the learning goals; (3) the teacher and the lesson design. The checklist clearly indicates that DI requires a repertoire of teaching methods. Most elements mentioned in both models for DI are supported by evidence-based research, however the application of flexible grouping and the use of learning styles for DI are discussed. This checklist may aid teachers to assess and improve their own teaching practice.
\end{abstract}

Keywords Differentiated Instruction, Checklist, Teacher Professional Development, Evidence-informed Education

\section{Introduction}

As diversity in many European countries increases, the need for educational innovation increases concurrently. Diversity in schools is not only a cultural diversity that has roots in historical and recent migrations it also may be presented as a pedagogical diversity in terms of differences in readiness level, interests or learning profiles. Diversity challenges teachers to take the micro-perspective of students as a starting point from which any educational process must take off. Designing education that takes into account diversity is now one of the priorities of educational policymakers $[1,2]$. Teachers are supposed to provide educational opportunities for a variety of different learners in their classrooms. In Flanders, where this study was held, this is supposed to be an elementary teacher competence [3].

Reality is often different. Many teachers regard the ambition to provide inclusive teaching opportunities for a variety of students as a difficult task. Many teachers don't know how to adapt their teaching habits to the new demographic reality or see this challenge as hard to address [4]. They often feel a lack of support and find it sometimes hard to imagine how a differentiated classroom could work $[5,6]$.

Different approaches are proposed to handle differences in the classroom and thus to provide inclusive educational opportunities for a wide variety of learners. Tomlinson $[7,8]$ proposed the concept of differentiated instruction as a framework that includes a variety of teaching strategies and methods aiming at maximizing learning profit for all learners in a classroom. An essential feature of the framework is that instructional design is not only related to learning goals such as targeted in the curriculum, but also based upon students' characteristics. Coubergs et al. [9] describe this 'ethical compass' as one of the theoretical foundations of teachers' perceptions about differentiated instruction. Another essential element is that teachers invest in ongoing assessment in order to be able to tailor instructional design to students' characteristics. The model of Hall (figure 1) provides a visual representation of these essential features of differentiated teaching. 


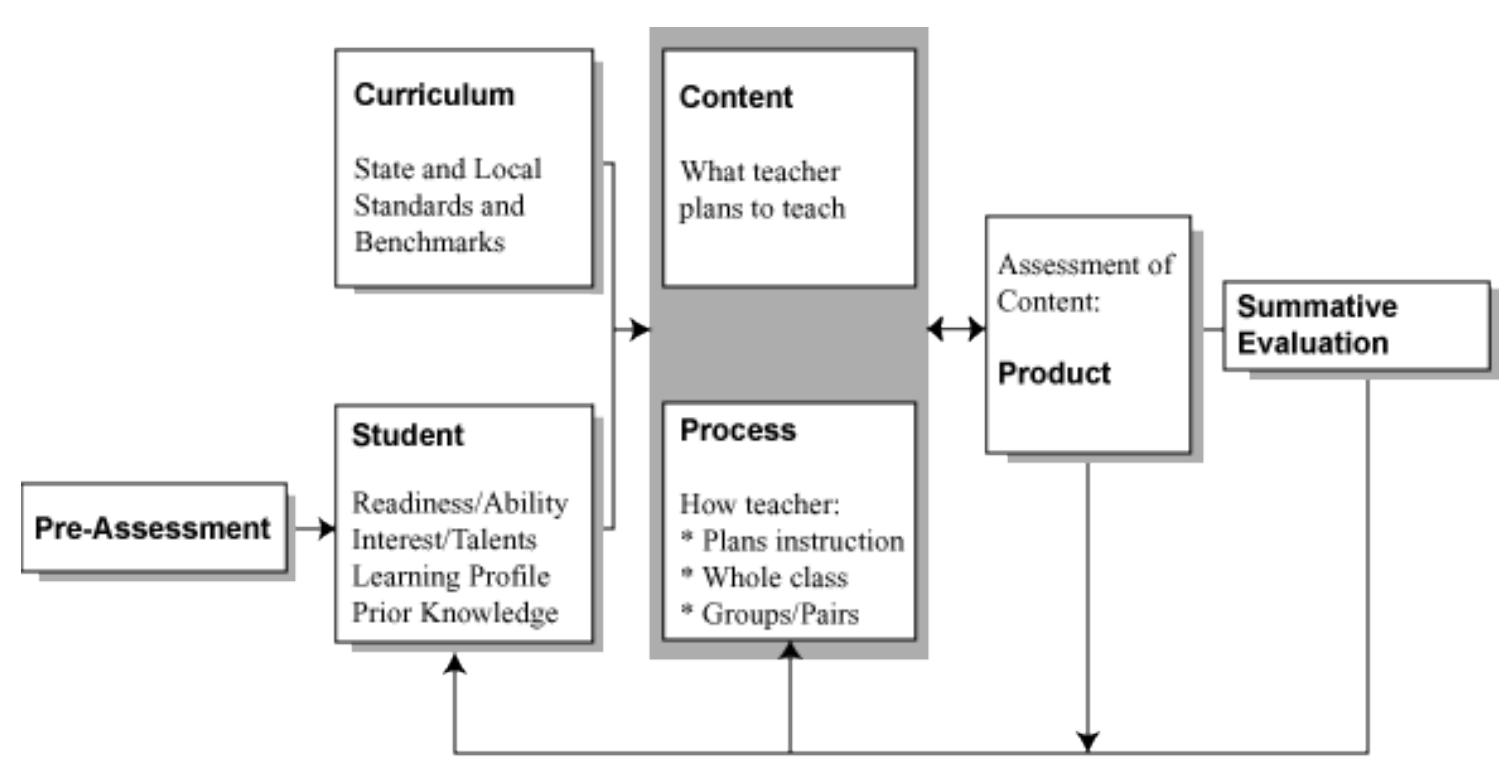

Figure 1. The cyclical process of differentiated instruction [10], adapted from Oaksford and Jones [11]

The comprehensive character of differentiated instruction makes it sensitive to critique as it is difficult to state whether DI is an effective classroom practice. Research on effectivity of DI is scarce and focuses on elements of the construct rather than on the construct as a whole (Firmender, Reis, \& Sweeny, 2013; Riviou \& Kouroupetroglou, 2014; Smit \& Humpert, 2012). The concept of differentiated instruction has until now not been going through academic effectivity research. This is probably due to the difficulty of developing a research design that is suitable for analyzing such a broad teaching concept.

Our ambition is to do full right to the complexity of the subject without staying blind for the need of practice-oriented research findings. The aim of this study is to bridge the gap between academic research on teaching effectivity and practice-based research on differentiated instruction, by providing an instrument that scaffolds teachers' decision-making. Through a systematic comparative approach an evidence-informed [12] checklist is introduced which may support teachers when they are innovation their teaching habits.

\section{Method}

Checklist-methodology was chosen based on Scriven's recommendations for research dissemination [13]. The checklist that is proposed in this study is based upon a systematic comparison of academic and practice-oriented research. Checklist methodology is broadly used with regard to quality control in highly complex environments. In this study Shufflebaums guidelines for developing checklists are used for this purpose [14]. The following descriptions intend to clarify the process of development of the checklist, and to explicit the most important choices that were made.

\subsection{Sample and Scope}

Important practice-oriented research on differentiated instruction has been conducted by researchers of the ASCD. The most well-known expert in the field is Tomlinson who has published extensively on the topic $[7,8,15]$. In Belgium, where this study was conducted, the largest research expertise on the matter is centered at the university of Brussels were Struyven and Coubergs have built up substantial experience [16-18]. The research for the 'checklist high quality differentiated instruction' started from two models for differentiated instruction that were developed by each of these experts $[8,16]$. The goal of this study is to systematically verify to which extent the suggested teaching strategies that are proposed by these experts are reflected in meta-analytical literature on teaching effectivity. Three comprehensive sources of educational effectivity literature were chosen as a source to make these verifications. Operational characteristics such as described in 2.2 were systematically compared with assertions in these three reference-works in general teaching effectivity. The selected works are to be seen as expert-references in the field [19-21] of educational effectivity. The choice to work with these generalist summaries for effective teaching is argued on the fact that many teachers in practice use these works as a reference.

\subsection{Operational Characteristics of Differentiated Instruction}

Both models of differentiated instruction were analyzed and summarized into a set of eight operational characteristics. The characteristic of the model of Coubergs, Struyven [16] is a translation of the author of the original Dutch version. 
Table 1. Set of operational characteristics of differentiated instruction.

\begin{tabular}{|c|c|c|c|}
\hline Tomlinson & Coubergs \& Struyven & Operational characteristics & \\
\hline Teacher's response to learner's needs & Handling differences & $\begin{array}{l}\text { Teacher reacts to different student characteristics } \\
\text { depending on student's needs. }\end{array}$ & A \\
\hline $\begin{array}{l}\text { Adapting to students readiness, } \\
\text { interests, learning profile }\end{array}$ & $\begin{array}{l}\text { Interest, learning profile, learning } \\
\text { status: aiming at maximizing } \\
\text { learning }\end{array}$ & $\begin{array}{l}\text { Teacher adapts to differences in learning status, interest } \\
\text { and/or learning profile aiming at maximizing learning. }\end{array}$ & $\mathrm{B}$ \\
\hline \multirow[t]{3}{*}{ Respectful tasks } & & Teacher adopts respectful attitude towards students. & $\mathrm{C}$ \\
\hline & $\begin{array}{l}\text { Teacher philosophy: growth } \\
\text { mindset \& ethical compass } \\
\text { towards student }\end{array}$ & $\begin{array}{l}\text { Teacher acts following principles of growth mindset } \\
\text { Teacher's ethical compass is directed towards students }\end{array}$ & $\mathrm{D}$ \\
\hline & Positive, proactive, planned & $\begin{array}{l}\text { Teachers handles differences in a positive, proactive and } \\
\text { planned way }\end{array}$ & $\mathrm{E}$ \\
\hline $\begin{array}{l}\text { Differentiation of content, process or } \\
\text { product }\end{array}$ & & $\begin{array}{l}\text { Teacher makes adaptations to content, process and } \\
\text { product }\end{array}$ & $\mathrm{F}$ \\
\hline Flexible grouping & Flexible grouping & Teacher uses flexible grouping & $\mathrm{G}$ \\
\hline Ongoing assessment and adjustment & Input $=$ output & $\begin{array}{l}\text { Teacher gathers continuously information } \\
\text { Teacher adapts lessons based on this information }\end{array}$ & $\mathrm{H}$ \\
\hline $\begin{array}{l}\text { Range of instructional and } \\
\text { management strategies }\end{array}$ & & $\begin{array}{c}\text { Teacher uses a range of instructional methods and } \\
\text { organizational strategies. }\end{array}$ & I \\
\hline
\end{tabular}

\subsection{High Quality Teaching}

This study is grounded in a perspective on teaching that is grounded in complexity science. 'Teaching is not a matter of applying a method or using a strategy; it is a matter of human interactions, within a complex network of interpretations and relationships' [22]. Given the complex nature of the learning sciences [23] teachers' are continuously challenged to interpret the plethora of recommendations that are provided by the educational sciences. A crucial determinant of promoting high quality teaching is enabling teachers' professional learning [24]. Therefore we believe it is vital to support their professional decision-making, by making research evidence more accessible. We agree with Biesta [25] that the complexity of the educational sciences cannot be reduced to simple 'what works' questions. Rather high quality teaching may be determined by evidence-informed teachers $[12,26]$ who reflect on their actions in order to foster and improve the quality of their own teaching practice. In order to facilitate this evidence-informed practice the checklist that is proposed in this study intends to present a large body of evidence related to differentiated teaching in an accessible way. Hence, suggestions are made for how to use the checklist for high quality differentiated instruction in the 'implications' section.

\subsection{Thematic Clustering}

Assuming that these meta-analyses provide a relevant overview of educational research, they were used as a reference to scrutinize the operational characteristics proposed in 2.2. A thematic analysis [27] was made of the elements in these studies that relate to the operational characteristics mentioned in table 1 . After initial coding, the results of the thematic analysis were clustered in the main themes that refer to three essential features of differentiated instruction which are also described in the introduction: (1) differentiated instruction adapts instructional design to students' needs; (2) differentiated instruction is not only based on curriculum goals, but also on student characteristics; (3) differentiated instruction is aimed at maximizing learning outcomes. It was a deliberate choice to present the first characteristic of adapting instructional design only as a third theme, because we believe both other themes are to be handled prior to instructional adaptations.

The first theme is grounded in the idea that teachers do not only base instructional design on curriculum targets, but that students characteristics are equally determinants for instructional design. As a result of this it is essential that the teacher relates to his or her students. This theme clusters a series of less tangible recommendations that nevertheless are vital for successful differentiated instruction. A second cluster refers to curriculum standards and other learning goals. In order to be able to provide tailored instruction, teachers appear to be very well aware of how to address the targeted learning goals. Clearly this theme relates to the idea of maximizing learning outcomes. Important is that ongoing assessment is used to provide both students themselves and teachers with feedback of what has been learnt and feed-forward of what is to be learnt. The third theme is the most evident one, as it addresses questions on instructional design and classroom management. Evidently the wide variety of teaching strategies that are used for differentiated instruction could not be integrated in the checklist. However, it was chosen to cluster them in more generalist checklist items that summarize the main elements.

\section{Results}

The comparison of practice-oriented expertise of Tomlinson on the one hand, and Coubergs and Struyven on 
the other hand with international literature on teaching effectivity resulted in three sets of characteristics of high quality differentiated instruction. These characteristics are more specified than the operational elements we found in the models of Tomlinson and Coubergs \& Struyven. In this section each of the sets is shortly explained.

\subsection{The Teacher and his/her Students}

The teacher stands in close relation with his/her students. Opportunities to discuss with students about their learning are offered. This implies that the teacher cannot be continuously talking and that questions are equally distributed between the teacher and the students. By considering social relationships between students the teacher creates a safe climate where learning is possible for anyone. In this climate failure is possible and even encouraged as it proves that a student is giving effort to leave the proper zone of comfort. The teacher gathers assessment data in order to integrate them in the student's learning process. The teacher does not let himself be guided by labels, but uses information on the student as a start of a learning process. Fundamental is a growth mindset towards students' learning possibilities. By setting high, but not necessarily equal, expectations the teacher helps them to set high expectations for themselves.

Table 2. criteria "The teacher in relation to his/her students"

\begin{tabular}{|c|c|}
\hline \multicolumn{2}{|c|}{ The teacher... } \\
\hline$\square$ & $\begin{array}{l}\text { Shows interest for the students and relates to them with regard to } \\
\text { their learning }\end{array}$ \\
\hline$\square$ & Installs a classroom culture where failure is possible \\
\hline$\square$ & $\begin{array}{l}\text { Has high expectations for all students and help them surpass } \\
\text { themselves }\end{array}$ \\
\hline$\square$ & $\begin{array}{l}\text { Has a well-balanced view on students with knowledge of } \\
\text { personal characteristics and without one-dimensional } \\
\text { stereotyping }\end{array}$ \\
\hline$\square$ & $\begin{array}{l}\text { Considers learning attitude and habits of students, and helps } \\
\text { improving these }\end{array}$ \\
\hline
\end{tabular}

\subsection{The Teacher and the Learning Goals}

The teacher is well aware of the goals he/she pursuits. $\mathrm{He} / \mathrm{she}$ understands the levels of and interconnectedness between learning goals and has insight in how learning goals can be attained trough different learning paths. In structuring learning goals to complexity the teacher creates challenges that fit with students' personal readiness level. By clearly stating the desired level of competence at the end of the learning process, and by formulating intermediary goals the teacher specifies for students what is expected. During the learning process the teacher provides ongoing formative assessment in order to give students insight was has and what has not been learned yet. This formative assessment provides students with insight in the proper learning path, and creates for the teacher the opportunity to adapt his/her lessons to it. The assessment data are thus not only an assessment of learning but also an assessment for learning.
Table 3. Criteria "The teacher and the learning goals"

\begin{tabular}{|ll|}
\hline The teacher... \\
\hline$\square \quad \begin{array}{l}\text { Understands learning goals and know how to structure them } \\
\text { towards complexity }\end{array}$ \\
\hline$\square \quad$ Provides students with insight in the learning path to follow \\
\hline$\square \quad \begin{array}{l}\text { Provides students with feedback of what has been learned, and } \\
\text { feed-up for what still needs to be learned }\end{array}$ \\
\hline$\square \quad \begin{array}{l}\text { Gathers assessment data on what has been learned, and uses this } \\
\text { in the future teaching design. }\end{array}$ \\
\hline
\end{tabular}

\subsection{The Teacher and the Lesson Design}

At the start of a learning process a teacher always builds on what students already know and can. Study materials are thus never entirely new. Thanks to a rich set of teaching strategies the teacher is capable of meeting students' diverging educational needs. The choice of teaching strategies is always based upon maximizing learning outcome for all students in the class. Hence they are always adapted to where students are in the learning process. By adapting to students' interests, learning profiles and readiness levels the teachers makes sure that anyone's learning process is enriched, where necessary or useful temporary homogeneous or heterogeneous collaborative learning groups are created to provide tailor-made instruction or learning materials.

Table 4. Criteria "The teacher and the lesson design"

\begin{tabular}{|l|}
\hline The teacher... \\
\hline$\square \quad$ Builds on existing knowledge, skills and attitudes \\
\hline$\square \quad$ Uses a diversity of different teaching strategies \\
$\square \quad \begin{array}{l}\text { Adapts the teaching strategy depending on where students are in } \\
\text { the learning process }\end{array}$ \\
\hline$\square \quad \begin{array}{l}\text { Uses flexible grouping depending on students interest, learning } \\
\text { profile and learning status }\end{array}$ \\
\hline
\end{tabular}

\section{Discussion}

\subsection{High Quality Differentiated Instruction}

Teachers that implement differentiated instruction in their classroom may use the models that were used in this study. Almost all of the elements in these models are explicitly mentioned by authors of international effectivity research as elements of good or effective teaching. It may be concluded that the framework of differentiated instruction as proposed by Tomlinson and may be regarded as good teaching practice. As such the operationalization of the used models for differentiated instruction can be a helpful guidance for teachers that want to address differences in the classroom. It helps bridging the gap between research and practice in the educational field [28]. Notwithstanding this, it may be clear that teaching is a complex activity, and that it is dangerous to simplify recommendations for high quality teaching. We are therefore convinced that high quality teaching is not only dependent on the quality of the strategies used, but above all 
dependent on the reflexive attitude of the teachers that implements the strategies. By acting reflectively [29] teachers may connect the challenges of everyday reality with the recommendations of scholarly educational sciences. The checklist we propose in this study may serve as a scaffold for this purpose.

The operational elements under scrutiny in this study resulted in a selection of checklist-criteria for high quality differentiated instruction. Some of them show important overlap with good teaching in general. In particular the elements of the first set of criteria that concern the relationship of the teacher with his or her students. Two elements deserve more specific comment as research is not entirely clear on how to bring them into practice. These elements are the aspect of flexible grouping and the aspect of considering learning styles.

\subsection{Flexible Grouping}

Experts on differentiated instruction promote the use of flexible grouping techniques. These techniques are in particular relevant with all kinds of cooperative learning activities. Flexible grouping permits teachers to accept different interests and different readiness levels in the same classroom as an opportunity rather than as a problem. Flexible grouping may also encompass using temporary homogeneous grouping. Research however is often negative on the possibility of homogeneous grouping. Both Hattie [19] and Muijs and Reynolds [21] are arguing against it.

It remains doubtful whether the contexts in which research warning against homogeneous grouping is an appropriate way to make statements on homogeneous grouping in differentiated instruction. It seems for instance not sure whether homogeneous grouping based on interests is really problematic. Still it emerges that homogeneous grouping based on readiness levels may be problematic as a result of decreasing students' self-efficacy and teachers' expectations, particularly if this kind of grouping is often practiced. These effects are important effects to consider for teachers that want to implement differentiated instruction.

\subsection{Learning Styles}

Much discussion has been made over de last few years on the matter of learning styles. This discussion must not be overdone here. However it is clear that the topic has been labeled problematic by many theorists, and that still a lot of practitioners see a substantial added value of different theories on learning styles.

With regard to differentiated instruction the question must here be whether teaching time sacrificed to framing a student's learning style is really spent effectively. Given the problematic character of learning styles we think it would not be advisable to lose much time on this topic. However some of the learning style models may help students to enhance their self-knowledge and could in this way provide some added value.

Another question is whether it makes sense to base students' assignments on a prior analysis of his or her learning style. Given the problematic character this topic the answer would be easily negative. Moreover, based on principles of self-determination it may be argued that students in a differentiated classroom should be provided with a maximum of choice to stimulate students autonomy, and therefore also motivation. If this integration of choice would encompass differences in learning styles where students are allowed to make choices depending on their own preferences probably no harm would be done.

\section{Implications for Teacher Education}

The introduction of differentiated instruction is often a long and difficult process that requires a lot of time [5, 30]. As a consequence it is not easy to prepare teachers for this difficult task. Intense professional development is needed for beginning teachers aiming at professional development to enable teachers to respond to differences in the classroom [31]. Also more experienced teachers do not always feel well prepared to engage in differentiated instruction [32]. As a result of that, teachers ask for support when they start introducing differentiated instruction [5]. Both in-service and pre-service teacher education is by consequence challenged to adapt its curriculum in order to prepare its students adequately for dealing with diversity in the classroom, and in particular for implementing differentiated instruction in their practice. We believe scaffolding is needed to support teachers' professional development. The checklist that is presented in this study may serve such a scaffolding purpose in order to foster the introduction of differentiated instruction.

The aim of the checklist that is presented in this article is to support pre-service and in-service teachers' evidence-informed decision-making when responding to student heterogeneity in the classroom. It may serve as a document for personal or collective reflections of teams of in-service teachers and teacher students. We illustrate this with three examples:

(1) As a response to increased heterogeneity a school chose for setting groups of students for mathematics. 4 hours per week students are grouped in homogeneous ability-groups across classes. Mathematics teachers adapt their instruction based on the ability group they are teaching to. One of the teachers however doubts whether this is a good idea. He thinks students in the low-ability group are being stigmatized as 'low performers', and he therefore wants to discuss the school's setting policy. On the monthly staff meeting this teacher uses the checklist to discuss his opinion with his colleagues: he believes the idea of setting ability-groups does not align with the idea of 'flexible grouping' in the 
checklist. He also point to the risk of low teacherand student expectations in the low-ability group for which the checklist warns.

(2) A teacher is used to work with Kolb's learning styles theory [33]. In the beginning of the year students of her are usually asked to fill out a questionnaire, and to reflect on their own preferred learning style. The teacher uses the survey-information to enable students to make a choice further on in the year. Based on the criteria "The teacher in relation to his/her students", she starts doubting whether this approach is a good idea. If feels as if this learning styles approach is a fairly one-dimensional approach. Based on this insight the teacher broadens her approach; focus lies now not on learning styles, but rather on other types of metacognitive skills by proposing the students a reflective assignment based on self-determination theory. The idea that teachers help improve students attitudes on learning (second set of criteria) is a support for to the teacher to keep on spending time to this important topic.

(3) A team of teachers intends to apply a strategy in which student get assignments tailored on their prior knowledge. However, the teachers realize that they lack the necessary assessment data in order to be able to do so. Using the checklist they realize they have underestimated the importance of the first two sets of criteria of the checklist. The conclude that in order to be able to provide high quality differentiated instruction, they need to relate stronger with their students in order to find out about their interests and prior knowledge. Moreover they decide to install formative assessments in order to gather more objective data on students' learning progress.

Given the complexity that has been described [34] of the learning sciences, we believe that no simple conclusions can be drawn with regard to teaching in a differentiated classroom. We agree with Cochran-Smith, et al. [35] that when 'what-works-questions' or 'what's best-questions' yield one-dimensional answers, they always result in a significant reduction of the complex reality. Therefore we believe administration of the checklist may not be reduced to a 'to-do-list'. Items of the checklist are no fixed do's or don't. On the contrary, they are guidelines that intend to stimulate reflective practitioners to assess their work. Moreover, this checklist for high quality differentiated instruction may serve as a scaffold for teachers who want to increase the quality of their teaching. When discussing the strategies they use or intend to practice, teachers may use the checklist as a point of orientation to build their reflective practice on [12].

\section{Conclusions}

Differentiated instruction is a construct that enables teachers to integrate differences amongst the students in their classroom into everyday teaching practice. This is why a checklist was developed for teachers to foster teachers' evidence-informed decision-making with regard to differentiated instruction with three set of categories: 'the teacher in relation to his/her students', 'the teacher and the learning goals', 'the teacher and the lesson design'. Most of the experts' recommendations are grounded in research on teaching effectivity. The implementation of differentiated instruction needs careful consideration as some concepts may be problematic. In particular the use of homogeneous ability grouping may be sometimes counterintuitive. The use of learning styles is even more problematic. All other operational elements in the models under scrutiny in this study may add to teachers' evidence-informed decision-making.

\section{REFERENCES}

[1] Raitano, M. and F. Vona, Peer heterogeneity, school tracking and students' performances: evidence from PISA 2006. Applied Economics, 2013. 45(32): p. 4516-4532.

[2] Schleicher, A.e., Preparing Teachers and Developing School Leaders for the 21st Century. Lessons from around the World. 2013, OECD: Paris.

[3] Vandenbroecke, F., Basiscompetenties voor de leerkracht secundair onderwijs. 2007, Vlaams ministerie van onderwijs.

[4] Gaitas, S. and M.A. Martins, Teacher perceived difficulty in implementing differentiated instructional strategies in primary school. International Journal of Inclusive Education, 2017. 21(5): p. 544-556.

[5] Smets, W., Binnenklasdifferentiatie. Lessen uit een innovatietraject. Impuls, 2016. 46(3): p. 115-121.

[6] De Neve, D. and G. Devos, How do Professional Learning Communities aid and Hamper Professional Learning of Beginning Teachers Related to Differentiated Instruction? (accepted). Teachers and Teaching: Theory and Practice, 2016.

[7] Tomlinson, C.A., Differentiating Instruction in Mixed-ability Classrooms. 2nd ed. 2001, Alexandria: Association for Supervision and Curriculum Development.

[8] Tomlinson, C.A., The Differentiated Classroom: Responding to the Needs of all learners. 2000, Alexandria: Association for Supervision and Curriculum Development.

[9] Coubergs, C., et al., Measuring teachers' perceptions about differentiated instruction: The DI-Quest instrument and model. Studies in Educational Evaluation, 2017. 53: p. 41-54.

[10] Hall, T.S., Nicole; Meyer, Anne, Differentiated Instruction and Implications for UDL Implementation. 2006, National Center on Accessing the General Curriculum.

[11] Oaksford, L. and L. Jones, Differentiated Instruction Abstract 2001, Leon County Schools: Tallahassee, Florida.

[12] Zwozdiak-Myers, P., The Teacher's Reflective Practice 
Handbook: Becoming an Extended Professional through Capturing Evidence-Informed Practice. 2012: Routledge, Taylor \& Francis Group.

[13] Scriven, D. The logic and methodology of checklists. 2005. 11.

[14] Stufflebeam, D.L., Guidelines for developing checklists. 2000, The Evaluation Center, Western Michigan University: Kalamazoo MI.

[15] Tomlinson, C.A., et al., Differentiating Instruction in Response to Student Readiness, Interest, and Learning Profile in Academically Diverse Classrooms: A Review of Literature. Journal for the Education of the Gifted, 2003. 27(2-3): p. 119-145.

[16] Coubergs, C., et al., Het BKD-leer-krachtmodel: binnenklasdifferentiatie realiseren in de klas. Impuls, 2015. 45(3): p. 151-159.

[17] Coubergs, C., et al., Binnenklasdifferentiatie: leerkansen voor alle leerlingen. 2013, Mechelen: Wolters - Plantyn.

[18] Struyven, K., et al., Mythes over binnenklasdifferentiatie: naar een 'leer-kracht'ig model. Hermes, 2016. 59.

[19] Hattie, J., Visible learning. A synthesis of over 800 meta-analyses relating to achievement. 2009, London Routledge.

[20] Marzano, R.J., A Theory-Based Meta-Analysis of Research on Instruction. 1998, McREL: Aurora.

[21] Muijs, D. and D. Reynolds, Effective teaching: Evidence and practice. 3rd ed. 2011, Thousand Oaks, CA: Sage.

[22] Cain, T., Teachers' classroom-based action research. International journal of research and method in education, 2011. 34(1): p. 3-16.

[23] Bakker, C. and M. Montesano Montessori, Complexity in Education. From Horror to Passion. 2016, Rotterdam: Sense.

[24] Schleicher, A.e., Building a High-Quality Teaching Profession. Lessons from around the World. 2011, Paris: OECD Publishing.
[25] Biesta, G., Why 'What Works' Still Won't Work: From Evidence-Based Education to Value-Based Education. Studies in Philosophy and Education, 2010. 29(5): p. 491-503.

[26] Nelson, J. and C. Campbell, Evidence-informed practice in education: meanings and applications. Educational Research, 2017. 59(2): p. 127-135.

[27] Braun, V. and V. Clarke, Using thematic analysis in psychology. Qualitative Research in Psychology, 2006. 3(2): p. 77-101.

[28] McIntyre, D., Bridging the gap between research and practice. Cambridge Journal of Education, 2005. 35(3): p. 357-382.

[29] Kelchtermans, G., Who I am in how I teach is the message: self-understanding, vulnerability and reflection. Teachers and Teaching, 2009. 15(2): p. 257-272.

[30] Smit, R. and W. Humpert, Differentiated Instruction in Small Schools. Teaching and Teacher Education, 2012. 28(8): p. 1152-1162.

[31] De Neve, D. and G. Devos, How do professional learning communities aid and hamper professional learning of beginning teachers related to differentiated instruction? Teachers and Teaching, 2017. 23(3): p. 262-283.

[32] Wan, S.W.Y., Differentiated instruction: are Hong Kong in-service teachers ready? Teachers and Teaching, 2017. 23(3): p. 284-311.

[33] Kolb, A.Y. and D.A. Kolb, Learning styles and learning spaces: Enhancing experiential learning in higher education. Academy of Management Learning \& Education, 2005. 4(2): p. 193-212.

[34] Jacobson, M.J., M. Kapur, and P. Reimann, Conceptualizing Debates in Learning and Educational Research: Toward a Complex Systems Conceptual Framework of Learning. Educational Psychologist, 2016. 51(2): p. 210-218.

[35] Cochran-Smith, M., et al., The Challenge and Promise of Complexity Theory for Teacher Education Research. Teachers College Record, 2014. 116(5). 